\title{
RELÉS ELECTROMAGNÉTICOS Y ELECTRÓNICOS. PARTE II: INTERRUPTOR ELECTRÓNICO
}

\section{ELECTROMAGNETIC AND ELECTRONIC RELAYS. PART II: ELECTRONIC SWITCH}

Arturo Pérez París: Universidad de Alcalá de Henares. Madrid (España). arturo.perez@mixmail.com

\section{CURRÍCULUM VITAE}

Profesor de la Escuela Politécnica de la Universidad de Alcalá de Henares. Ingeniero electrónico y literato. Destacan sus estudios sobre aplicaciones eléctricas y motricidad sobre los que ha publicado varios artículos científicos.

\section{RESUMEN}

Los relés son los dispositivos destinados a producir determinadas modificaciones, cuando se cumplen ciertas condiciones en un circuito eléctrico que influyen sobre él, en el mismo circuito o en otro distinto. El circuito sobre el que actúa el relé sirve de control o de señalización. Es el mundo de los automatismos industriales. La función del relé electromagnético es similar a la del interruptor electrónico para circuitos de mando y a la del contactor para circuitos de potencia. Pero en cuanto a su constitución, las diferencias son notables porque no llevan partes móviles o, incluso, están formados por una única pieza. 


\title{
PALABRAS CLAVE
}

Relé - Interruptor electrónico - Tiristor - Triac

\begin{abstract}
The relays are devices designed to produce certain modifications, when certain conditions in an electrical circuit that influence him in the same circuit or in another. The circuit acts on the relay acts as a control or signaling. Is the world of industrial automation systems. The electromagnetic relay function is similar to the electronic switch control circuit and the contactor for power circuits. But in terms of its constitution, the differences are notable because they have moving parts, or even consist of a single piece.
\end{abstract}

\section{KEY WORDS}

Relay - Electronic switch - Thyristors - Triacs

TEXTO:

La definición dada para el relé, en la primera parte de este artículo publicada el mes pasado, cumple perfectamente para el concepto de interruptor electrónico. Buena prueba de ello es que éstos también se conocen con el nombre de relés electrónicos.

Su función es comparable a la del relé electromagnético para circuitos de mando y a la del contactor para circuitos de potencia. Abre o cierra circuitos que, a su vez, hacen 
otras funciones. En cuanto a su constitución, las diferencias son notables. Los dispositivos que pueden servir de interruptores o relés electrónicos son compactos. Esto es, no llevan partes móviles e incluso están constituidos por una sola pieza, eso sí, con varios terminales. Son ejemplos de ello el tiristor y el triac como elementos de conmutación de potencia. Y adviértase que sólo se consideran relés electrónicos aquellos circuitos que trabajan en todo o nada y no aquellos casos en los que se trata de regular el paso de corriente, función para la que también están capacitados estos elementos a través de la circuitería adyacente adecuada.

En aplicaciones prácticas, el control del tiristor puede ser tan complicado y preciso como lo requiera cada caso. Ahora bien, cualquier procedimiento estará basado en un circuito elemental, que puede llamarse de potencia, y otro de carácter de mando, generalmente más complejo, destinado precisamente a disparar y mantener cebado el tiristor, durante un número de ciclos positivos, y a bloquearlo también, durante varios ciclos positivos. De esto se desprende la semejanza con el interruptor: abre y cierra el circuito; conduce o no conduce. Los procedimientos de cebado que se exponen a continuación son elementales, pero conectados con otros circuitos conforman verdaderos equipos de control de todo o nada.

Como ya sabemos, un tiristor se cebará cuando, teniendo suficiente tensión entre ánodo y cátodo, reciba, a través de su puerta, un impulso de valor adecuado y duración suficiente. Este impulso puede ser controlado por un elemento tan simple como un interruptor, a saber: 


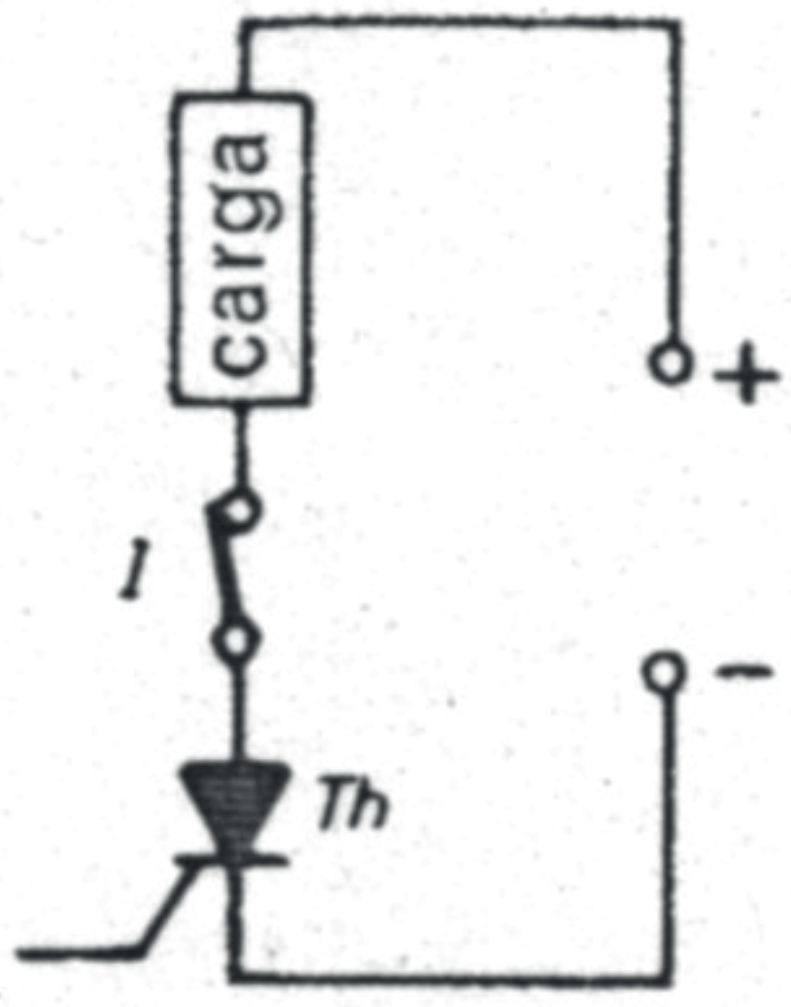

En este circuito se ha empleado el sistema de interruptor serie, pero también es factible el método del interruptor en paralelo: 


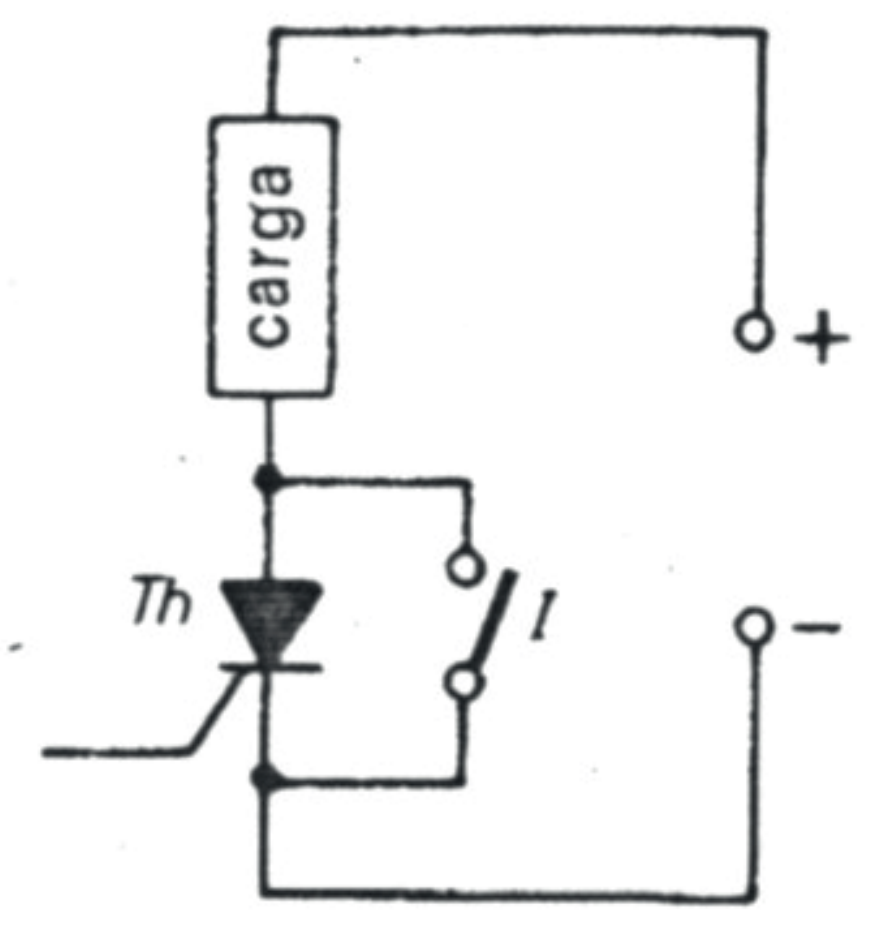

Como puede apreciarse en el segundo procedimiento, lo que se hace es cortocircuitar el tiristor cuando se desea su interrupción. A estos procedimientos se les denomina de conmutación natural, pero es obvio pensar en su limitada aplicación, debido a la imposibilidad de conseguir un interruptor mecánico que realice estas operaciones de cierre y apertura con la suficiente rapidez. La desconfianza proviene del aumento de la velocidad de crecimiento de la tensión directa que se produce por estos procedimientos, que pueden llevar a la conducción al tiristor, aun sin tensión en puerta. Por ello empleando estas ideas básicas de conmutación natural, podrían usarse transistores bipolares, que nos darán una más precisa y segura conmutación natural. Ésta se produciría actuando por el circuito siguiente: 


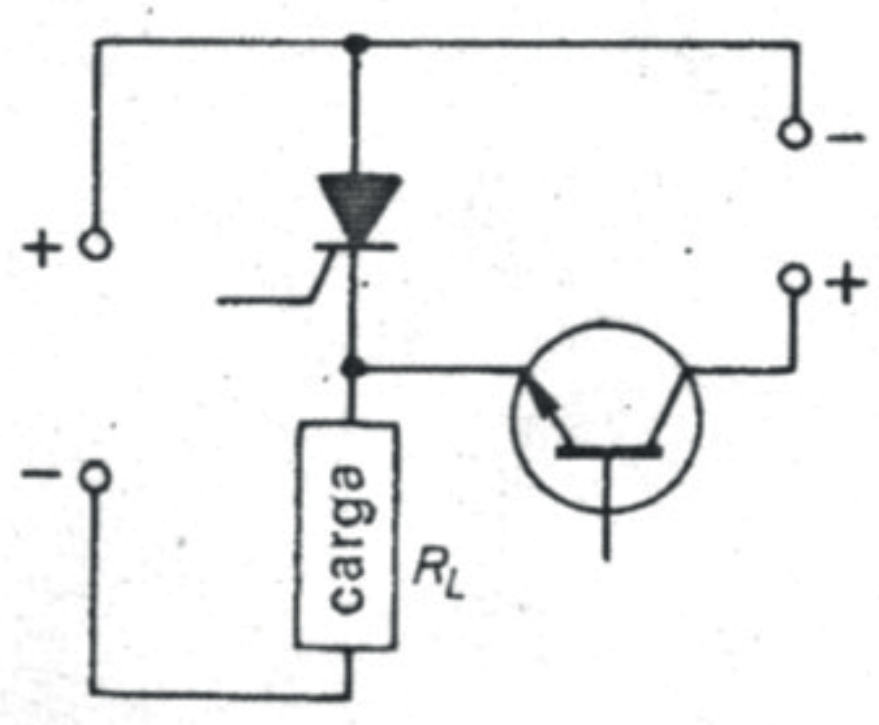

A 

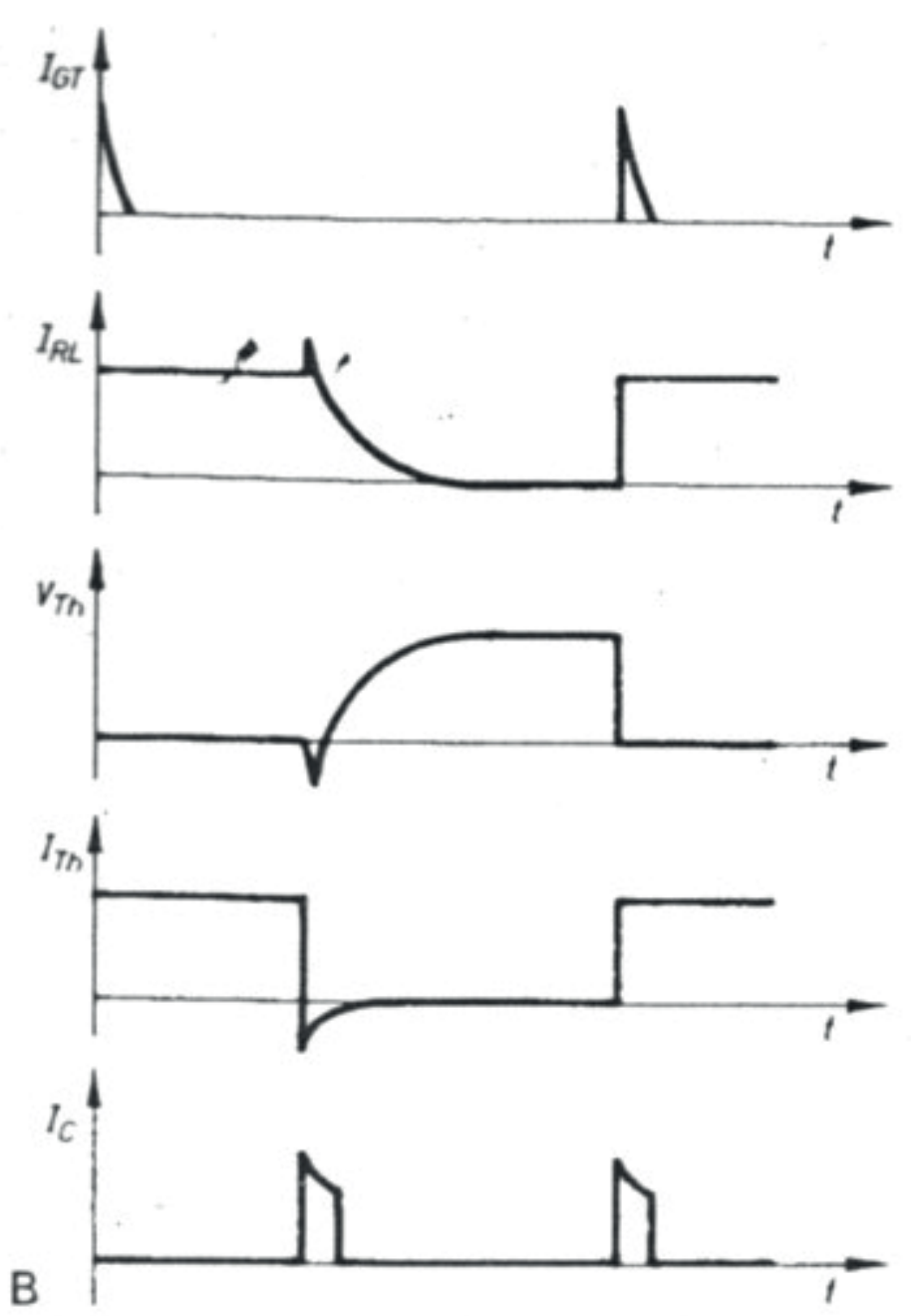

Este circuito produce la conmutación por medio de un transistor en paralelo con el tiristor, siendo así el transistor el que hace de interruptor en este caso.

Otra manera de realizar la conmutación de estos dispositivos es de forma forzada. Reciben este nombre todos aquellos métodos en los que la corriente se ve forzada a pasar a través del tiristor en sentido inverso. La ventaja de la conmutación forzada radica en que el tiempo de descebado es menor.

Por ejemplo, en la autoconmutación, de lo que se trata es de descebar al tiristor automáticamente una vez transcurrido un tiempo predeterminado desde la aplicación del impulso de disparo. Los circuitos más empleados en esta manera son: 
a) Circuito oscilante LC en paralelo.

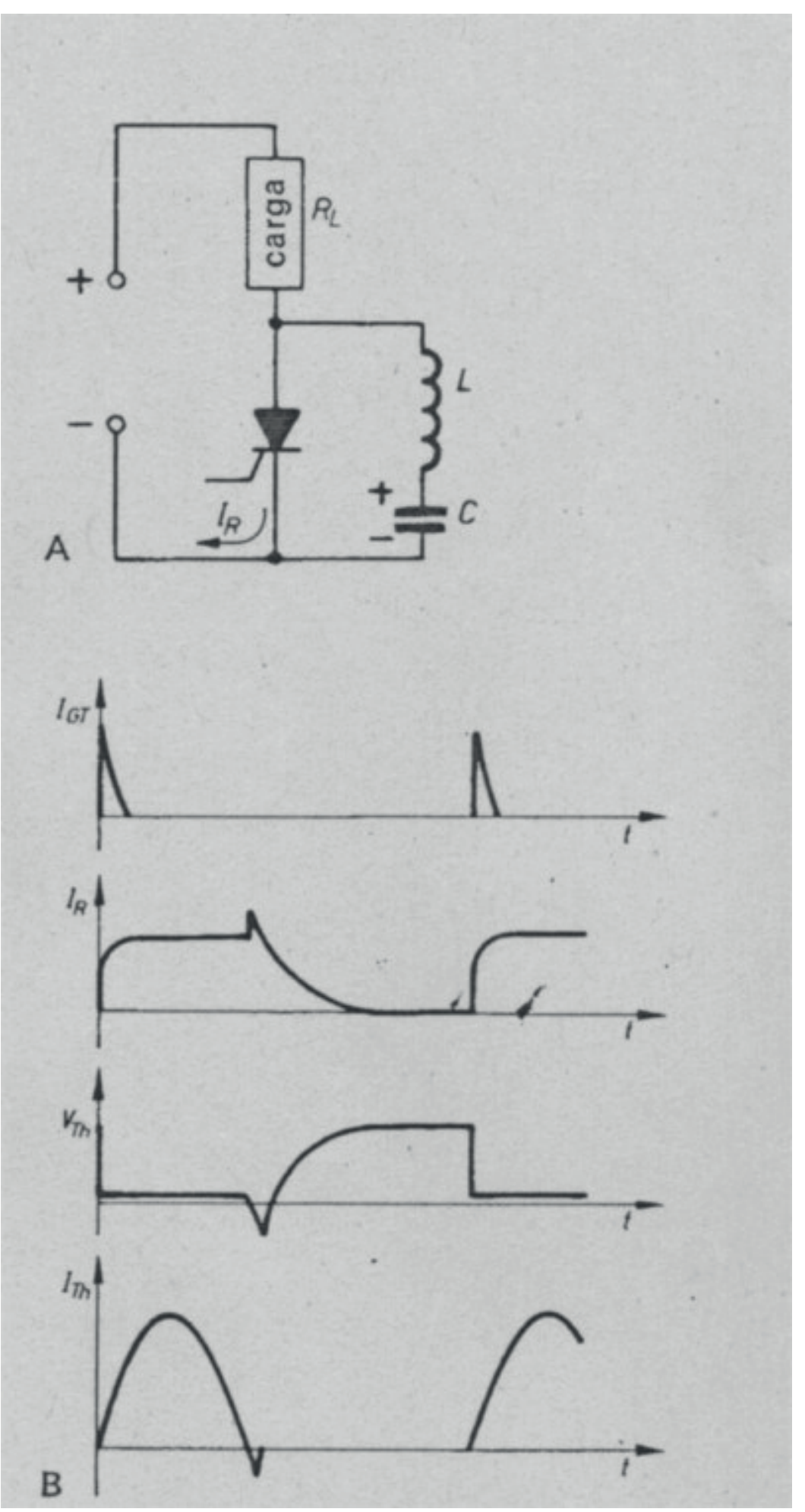


Supongamos que el tiristor está bloqueado. En estas condiciones el condensador se cargará con la polaridad indicada. Cuando se produce el disparo del tiristor, el condensador se descarga sobre éste en sentido directo. Una vez descargado, comienza a cargarse en sentido opuesto, debido a la oscilación del circuito LC, hasta que la corriente de carga es mayor que la directa del tiristor, momento en el que se produce el descebado.

b) Circuito oscilante LC en serie.

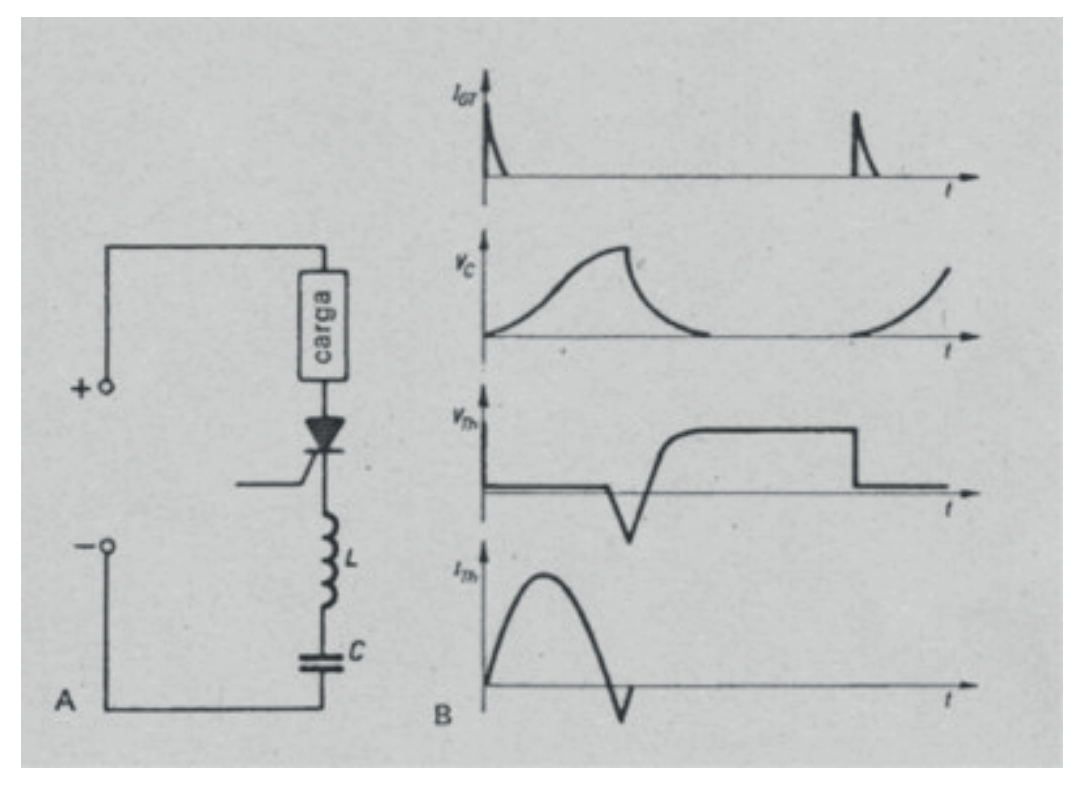

La corriente que circula cuando el tiristor se dispara excita al circuito LC. Transcurrido el primer semiciclo de la oscilación, la corriente se invierte y desceba el tiristor.

Los circuitos elementales más empleados para la conmutación forzada y que la producen sin depender del tiempo en que se produjo el disparo son: 
a) Conmutación por medio de corriente alterna. Que será el caso más elemental; pues, como ya es sabido, el tiristor se desceba cada vez que cambia el sentido de la tensión al semiperíodo negativo, debiendo tener la precaución de comprobar que la frecuencia no sea tan elevada que el tiempo de conmutación sea superior al del período de dicha frecuencia. 
Relé - Interruptor electrónico - Tiristor - Triac
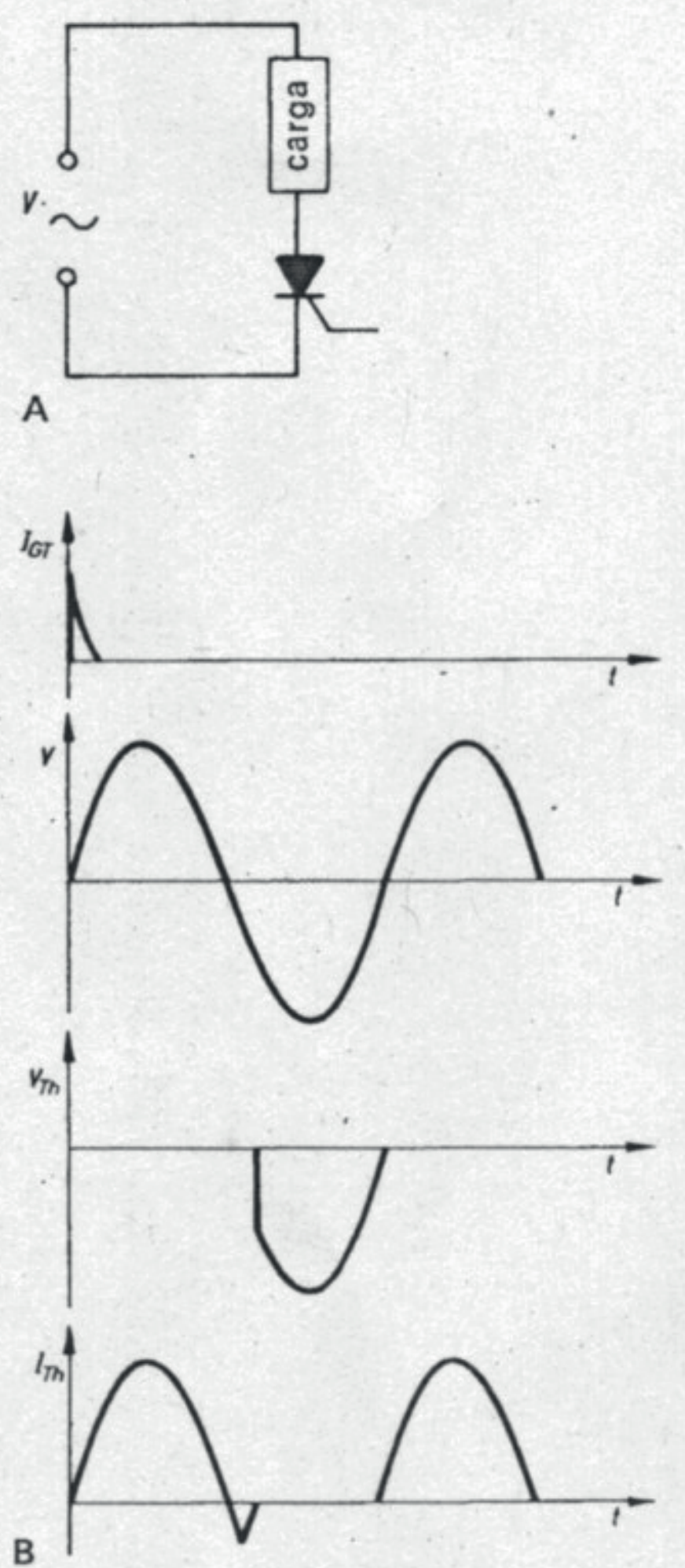

11

ISSN: 1575-2844 - DOI: http://dx.doi.org/10.15178/va.2003.51.1-38 
b) Conmutación por tiristor auxiliar. El disparo de Th1 carga el condensador con la polaridad indicada en la siguiente figura. Disparando el Th2, la placa positiva del condensador queda conectada a masa y el mismo condensador tiende a descargarse sobre Th1 y, por tanto, lo bloquea. El Th1 debe calcularse para ser recorrido por toda la corriente de carga mientras el Th2 puede ser calculado para una corriente mucho más pequeña. Su función es sólo la de interrumpir la conducción de Th1. 

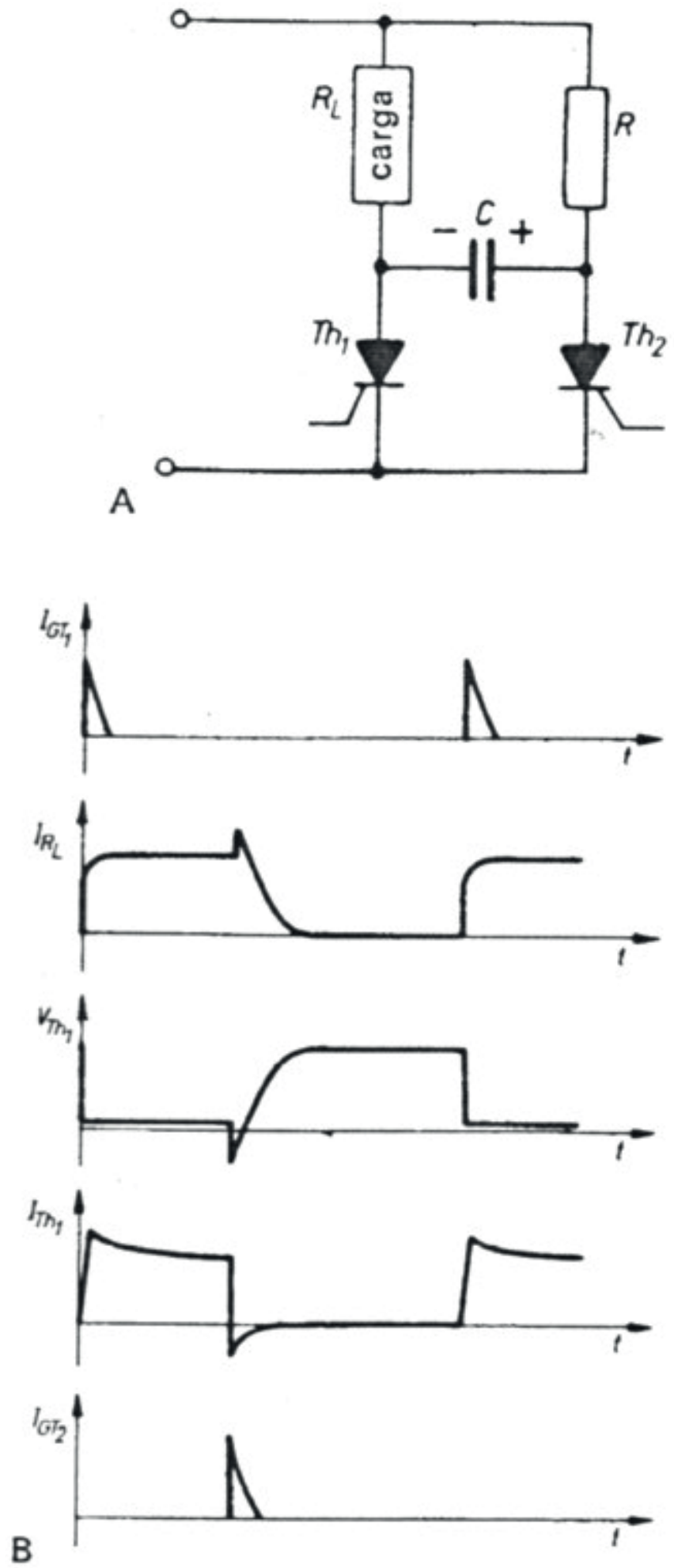
Una variante de este caso sería la que a continuación se expone:

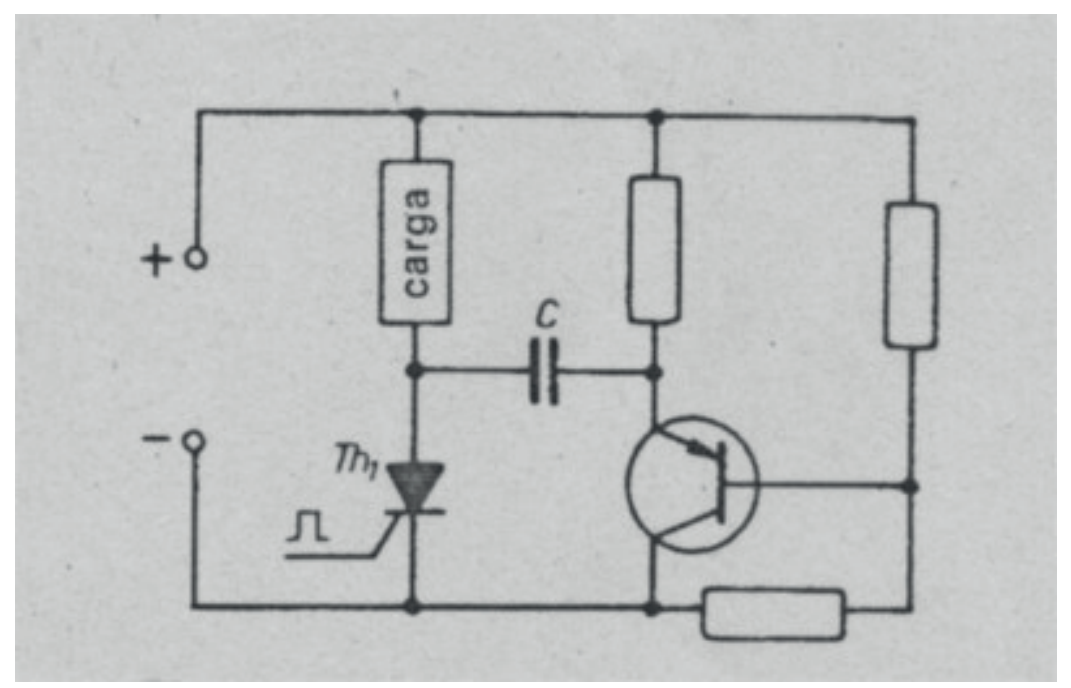

en el que se ha sustituido el tiristor auxiliar por un transistor. Otra, más elemental, sería la siguiente:

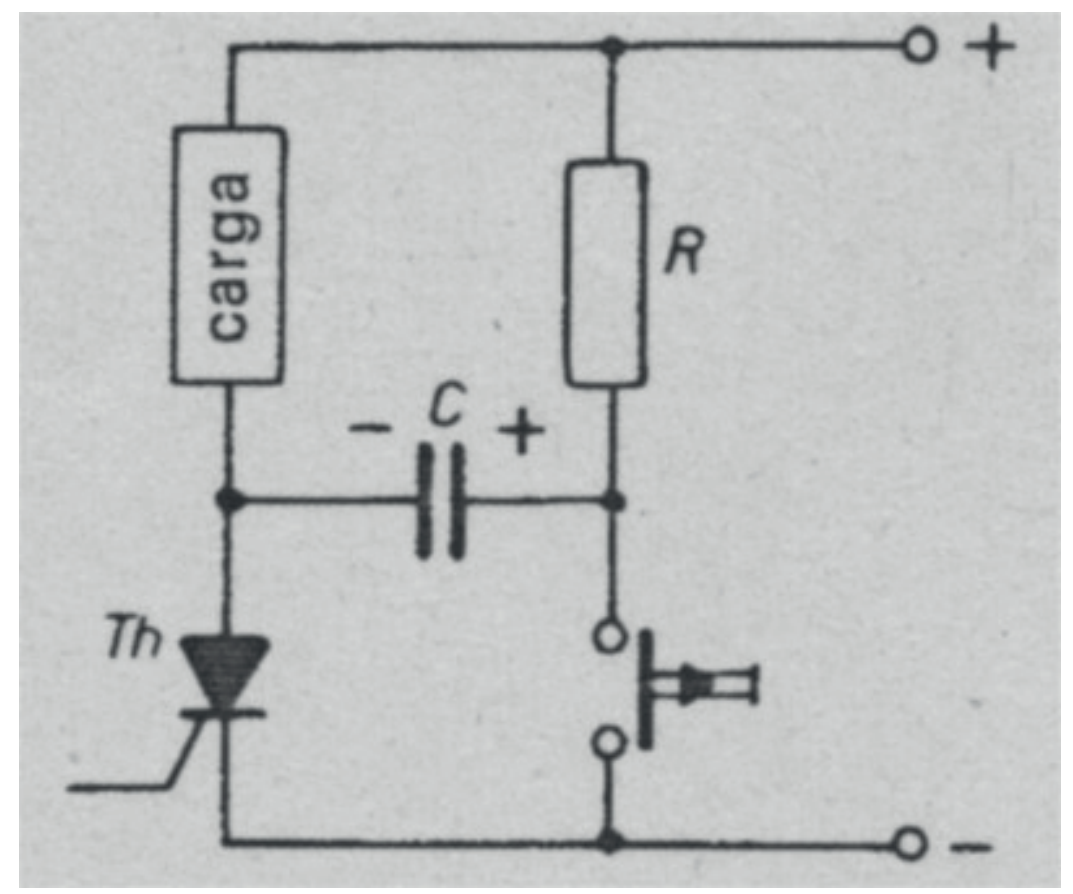

cuando se desee bloquear el tiristor bastará accionar el pulsador. 
c) Conmutación por generador de impulsos. Una vez cebado el tiristor, se conseguirá descebarlo enviando un impulso positivo, por medio del generador de impulsos, ya que, como se comprueba en el circuito, el transformador está conectado al cátodo del tiristor, a saber:
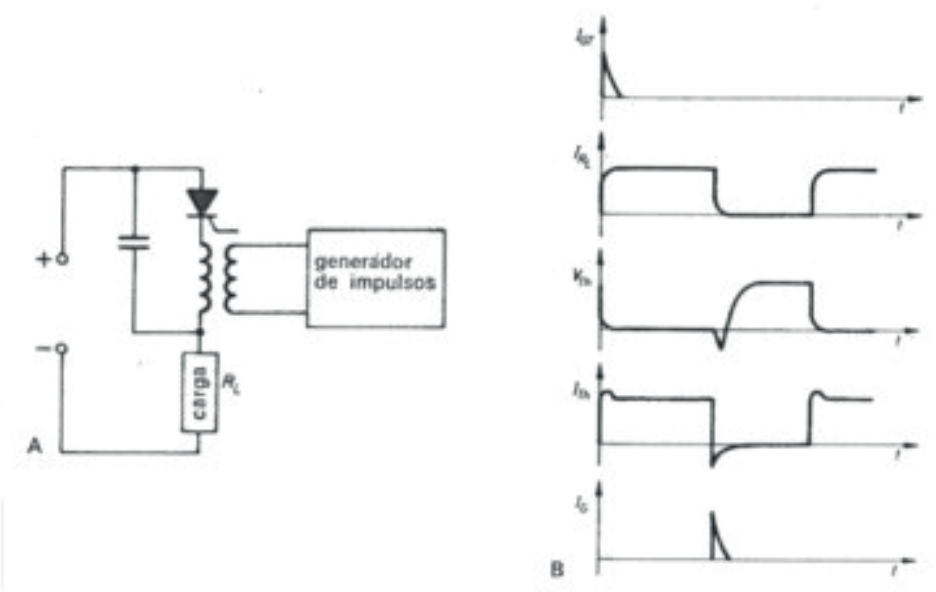

En el circuito que a continuación se expone, cuando el contacto A esté abierto, ambos tiristores estarán bloqueados. Cerrando el mencionado contacto, que puede ser un tiristor de pequeña potencia o un transistor o cualquier otro elemento de accionamiento, cuando el semiperíodo positivo polarice, por ejemplo, a Th1, el diodo D1, también estará polarizado directamente, enviando a la puerta de Th1, la señal que le pondrá en conducción. En el semiperíodo siguiente se bloqueará Th1 y D1 y sucederá lo descrito anteriormente, pero ahora con Th2 y D2. El resultado es que, durante el tiempo que A esté cerrado, la carga estará alimentada. 


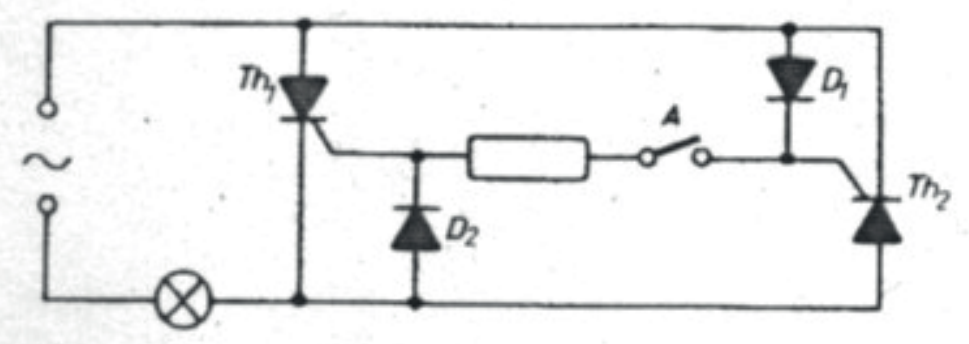

Implementando un circuito cuyo conmutador esté controlado por señal positiva se tendrá:

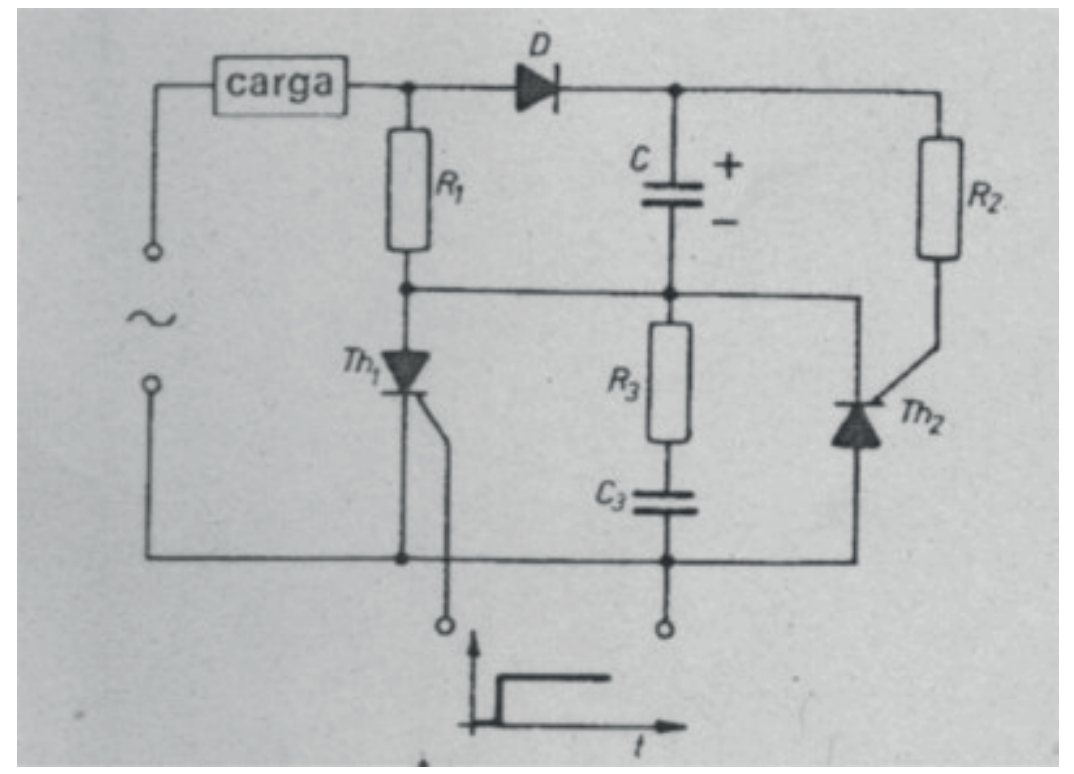

En él se ve que cuando la puerta de Th1 reciba una señal positiva y su tensión de ánodo también lo sea, conducirá, circulando la corriente por R1 y la carga. El condensador C se cargará con la tensión existente en bornes de R1. En el semiciclo negativo, C se descargará a través de R2 y Th2, cebando a este último. Este ciclo se repetirá hasta que la señal positiva aplicada en la puerta de Th1 cese. En este momento, dicho tiristor dejará de conducir y C no volverá a cargarse interrumpiendo el ciclo. La tensión recibida en la puerta de Th1 podría ser una onda cuadrada de una duración determinada y el tiempo de duración marcaría el de conducción del 
circuito. Esta señal la podría suministrar un transistor. El diodo D impide la descarga de C durante los semiciclos negativos. R3 y C3 evitan las sobrecargas de conmutación que se producirían sobre el tiristor.

Si la fuente que determina la conmutación del tiristor ha de ser una fuente lumínica, en primera instancia podría usarse el circuito:

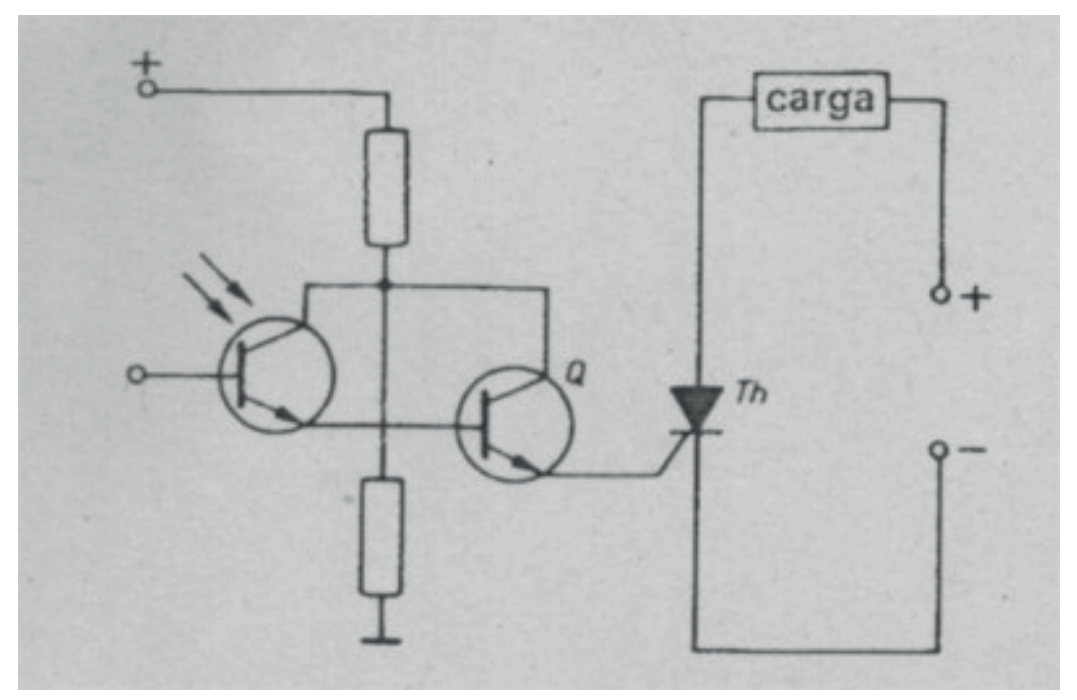

Cuando la luz incida sobre el fototransistor, el transistor $Q$ enviará una señal al tiristor, instante en el que pasa a conducir. Hay que decir que en el mercado nos podemos encontrar todo este conjunto integrado en una misma pastilla. Son los llamados fototiristores.

Para terminar, en el presente artículo con los tiristores, quisiera, como aplicación interesante, hablar de los denominados circuitos onduladores. Para convertir corriente continua en alterna, se puede disponer de un tiristor conectado como se ve a continuación: 


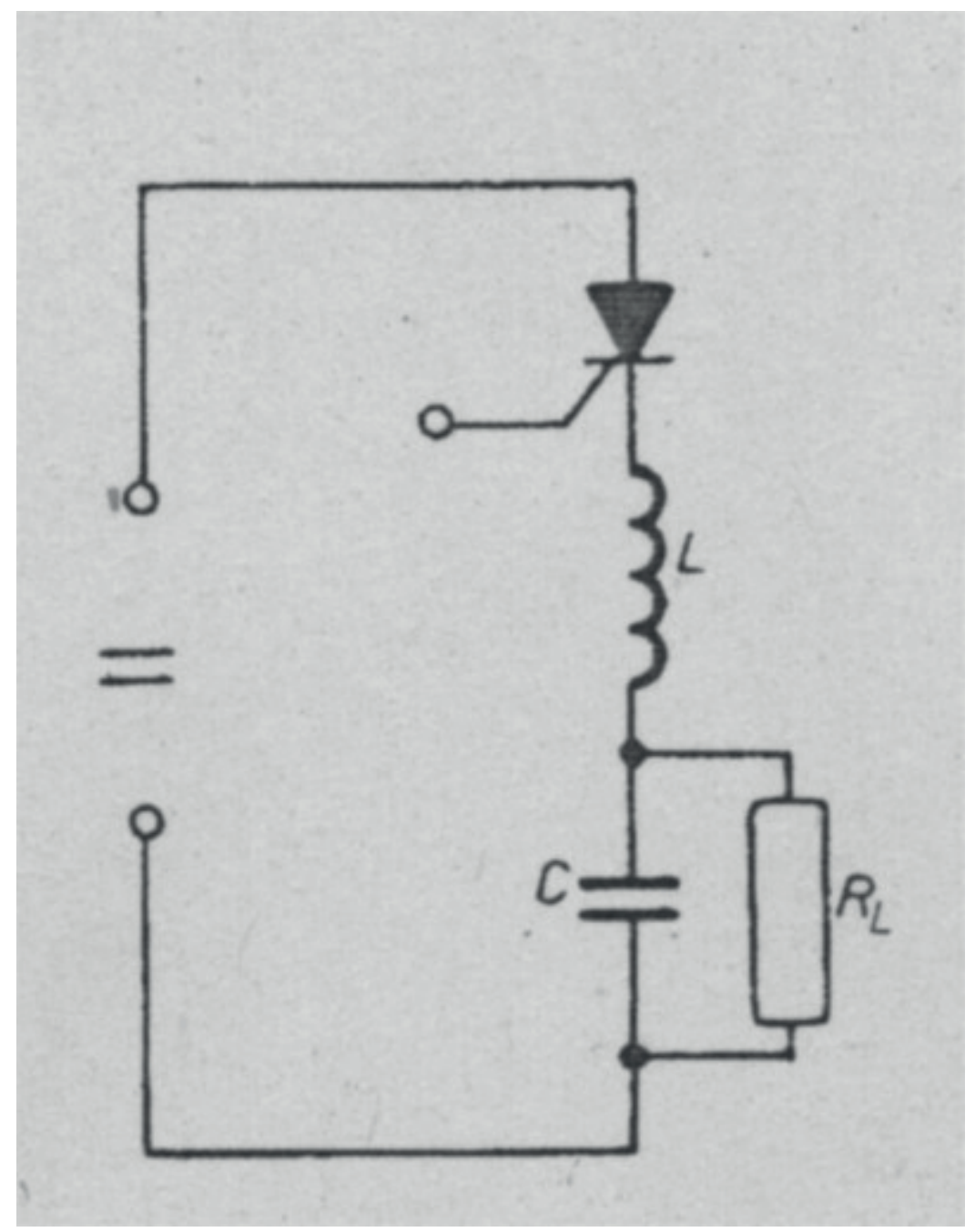

Cuando se cebe el tiristor, el circuito resonante serie LC recibirá un impulso que cargará el condensador y se producirá una oscilación. Transcurrido el primer semiciclo de la oscilación, se procede a descebar el tiristor y, en estas condiciones, el condensador comenzará a descargarse sobre RL, obteniéndose en bornes de la resistencia la siguiente la señal, ya que el ciclo se repetirá y aparecerán sucesivas señales casi triangulares: 


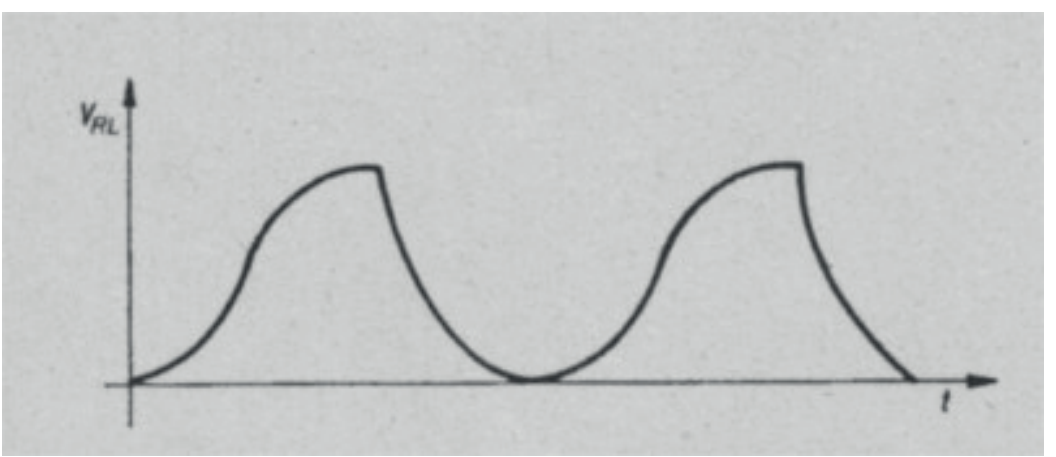

Para obtener una onda senoidal, se conectará otro tiristor, Th2 de la siguiente guisa:

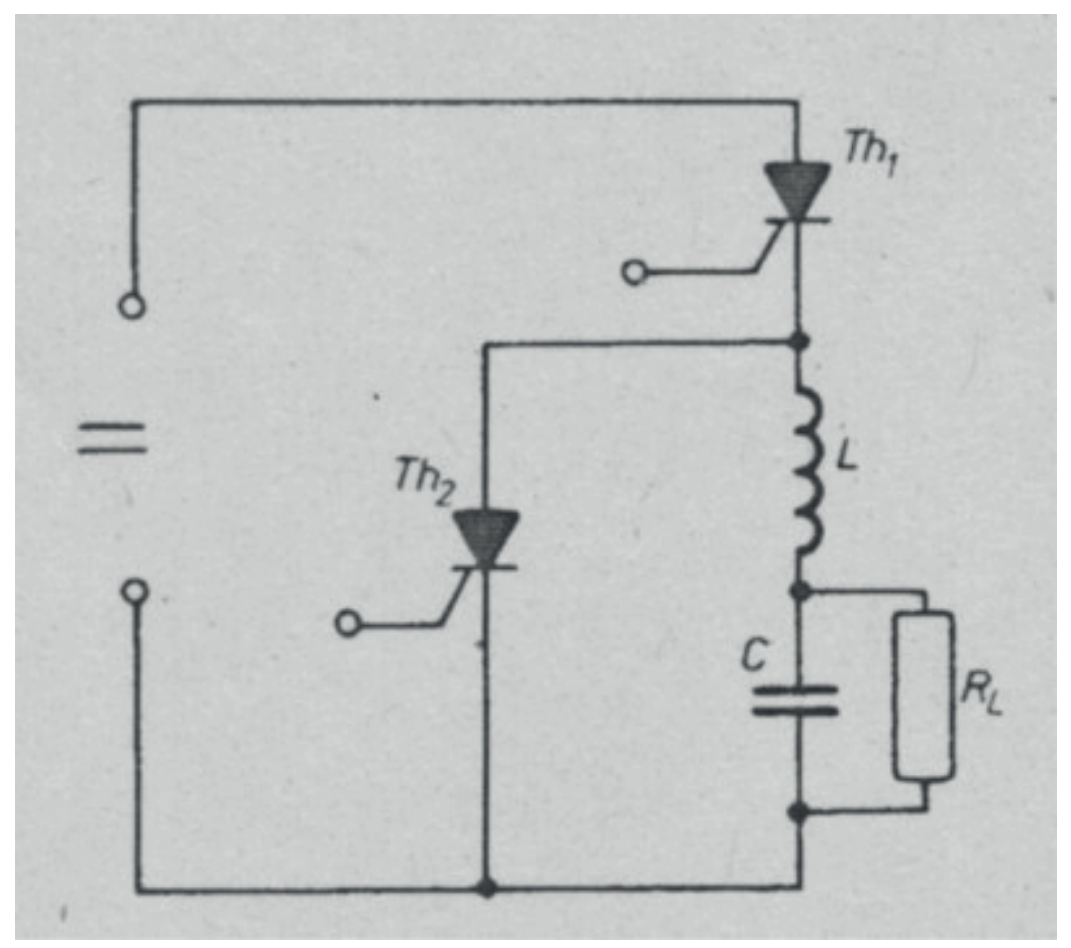

El mando de este tiristor deberá cebarlo cuando se descebe Th1. De esta manera, el condensador C se descarga a través de Th2, y en RL se obtendrá la senoide buscada. Cuando comience el semiciclo siguiente, se vuelve a conectar Th1 y repetiremos el proceso descrito. 


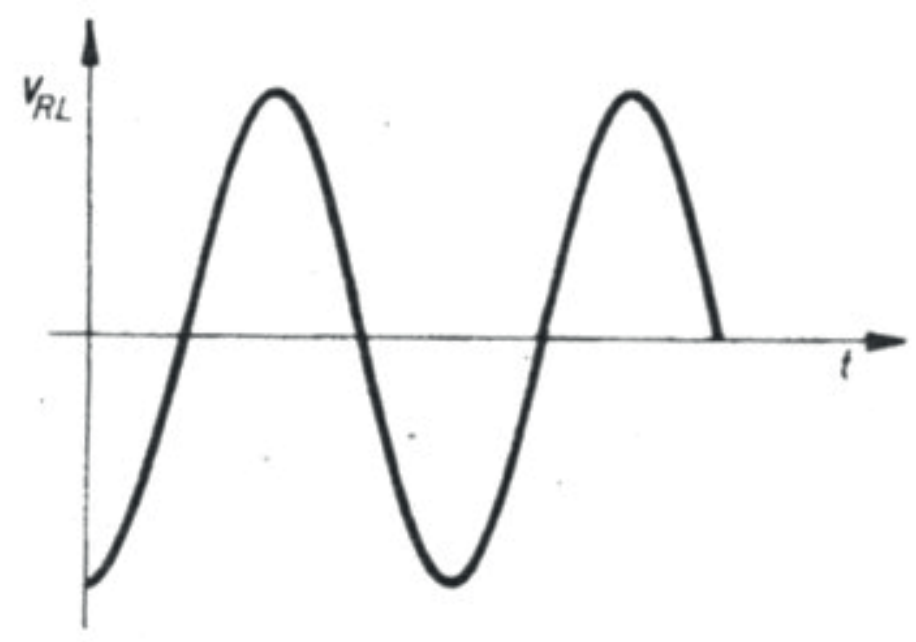

Para corriente alterna, el tiristor puede resultarnos un tanto engorroso en su uso. Para ello se dispone del triac. Sabiendo que el triac es un elemento bidireccional, es fácil llegar a la conclusión que, con este dispositivo, se podrá controlar una senoide completa. No sucedía así con el tiristor, que, cuando trabajaba con corriente alterna, sólo podía conducir en el semiciclo positivo, precisándose de dos tiristores conectados en antiparalelo si se quería controlar toda la senoide.

Salvando las diferencias que existen en la propia constitución física y las que de ello se derivan, puede afirmarse que el triac es capaz de sustituir a dos tiristores conectados en antiparalelo, lo que equivale a decir que su empleo puede ser el mismo y el sistema de mando muy semejante y, en algunos casos, idéntico. Para muestra de ello véanse los circuitos que seguidamente se muestran: 


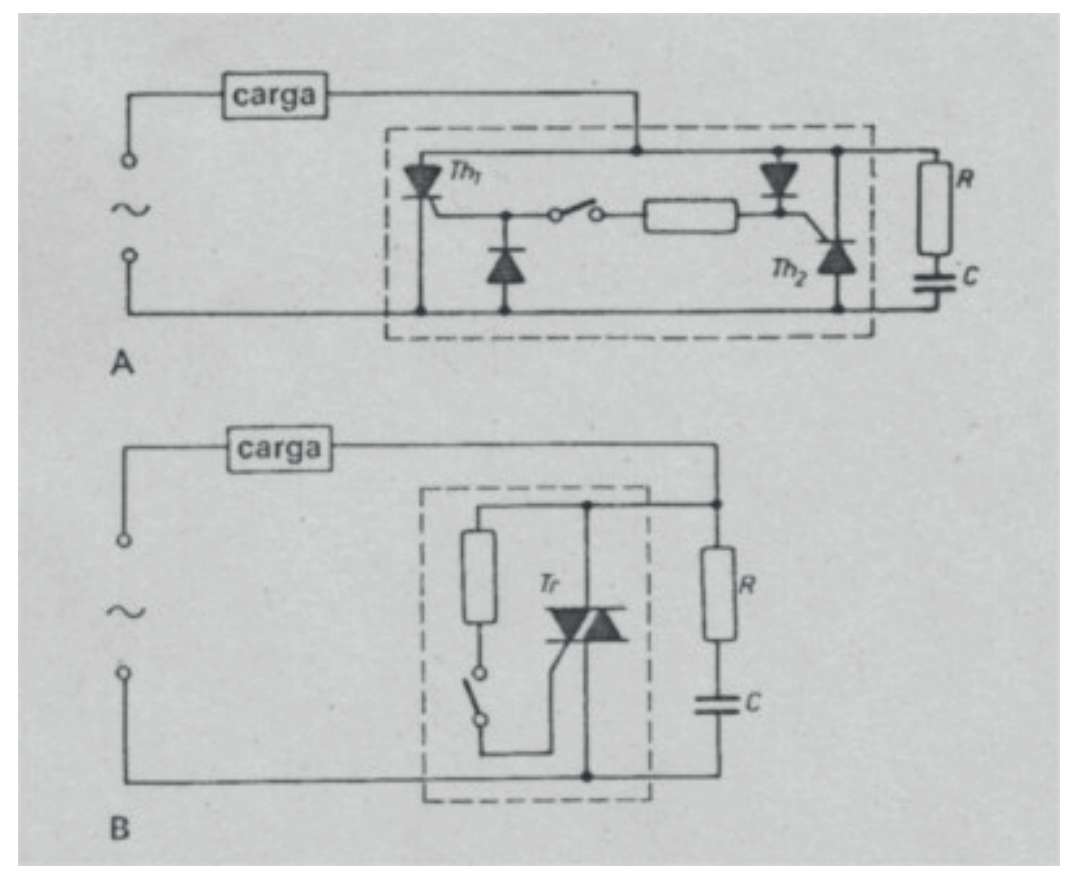

Otro ejemplo de lo que estamos hablando es el circuito siguiente, donde en este caso los impulsos de cebado proceden de un transformador de impulsos: 


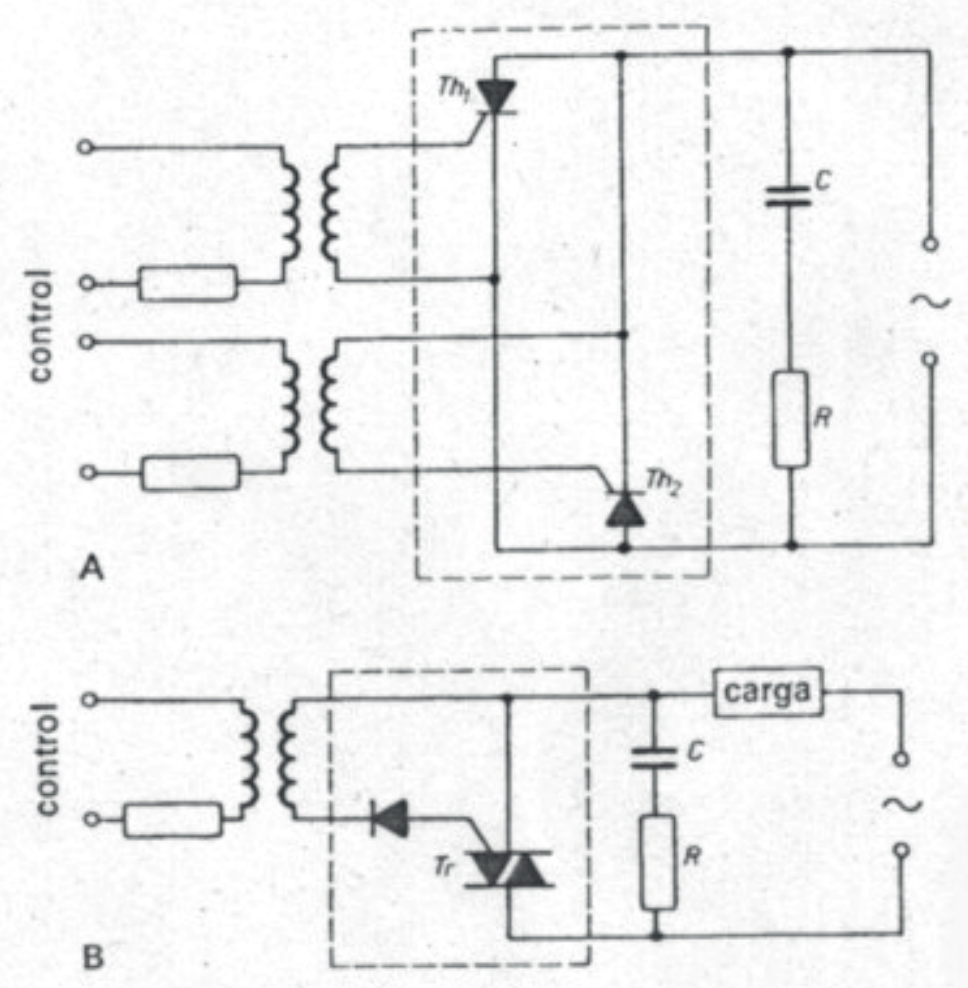

Como resultado de las distintas combinaciones de polarización que admite el triac, se obtienen los circuitos: 

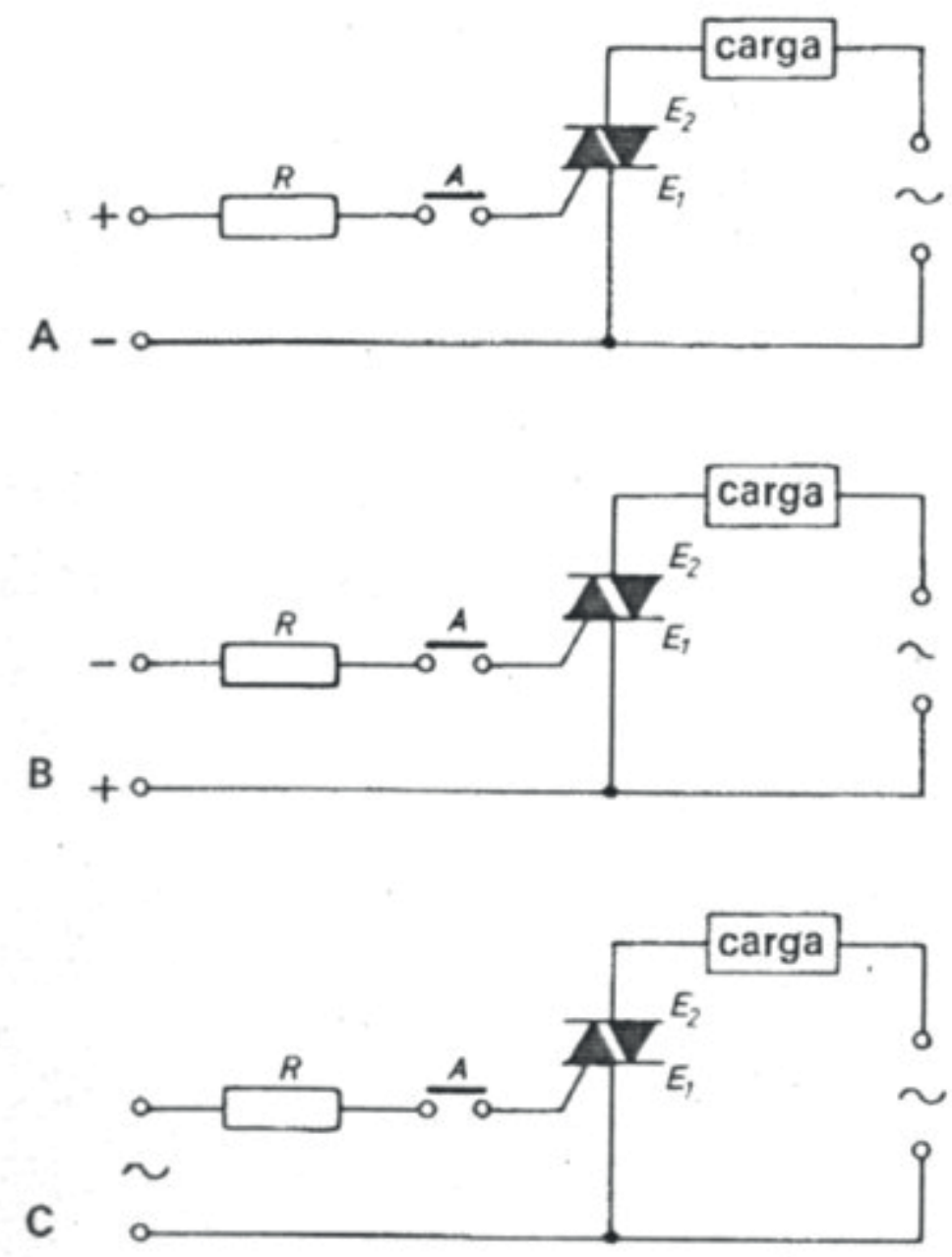

Como se observará, la tensión aplicada entre los terminales E1 y E2 es alterna. Usar el triac con alimentación en continua es emplear el dispositivo a la mitad de sus posibilidades. El contacto A podría sustituirse por un transistor, tiristor o triac auxiliar, obteniendo los circuitos que a continuación se muestran, donde se ve cómo un impulso aplicado al circuito de mando dispara el triac: 

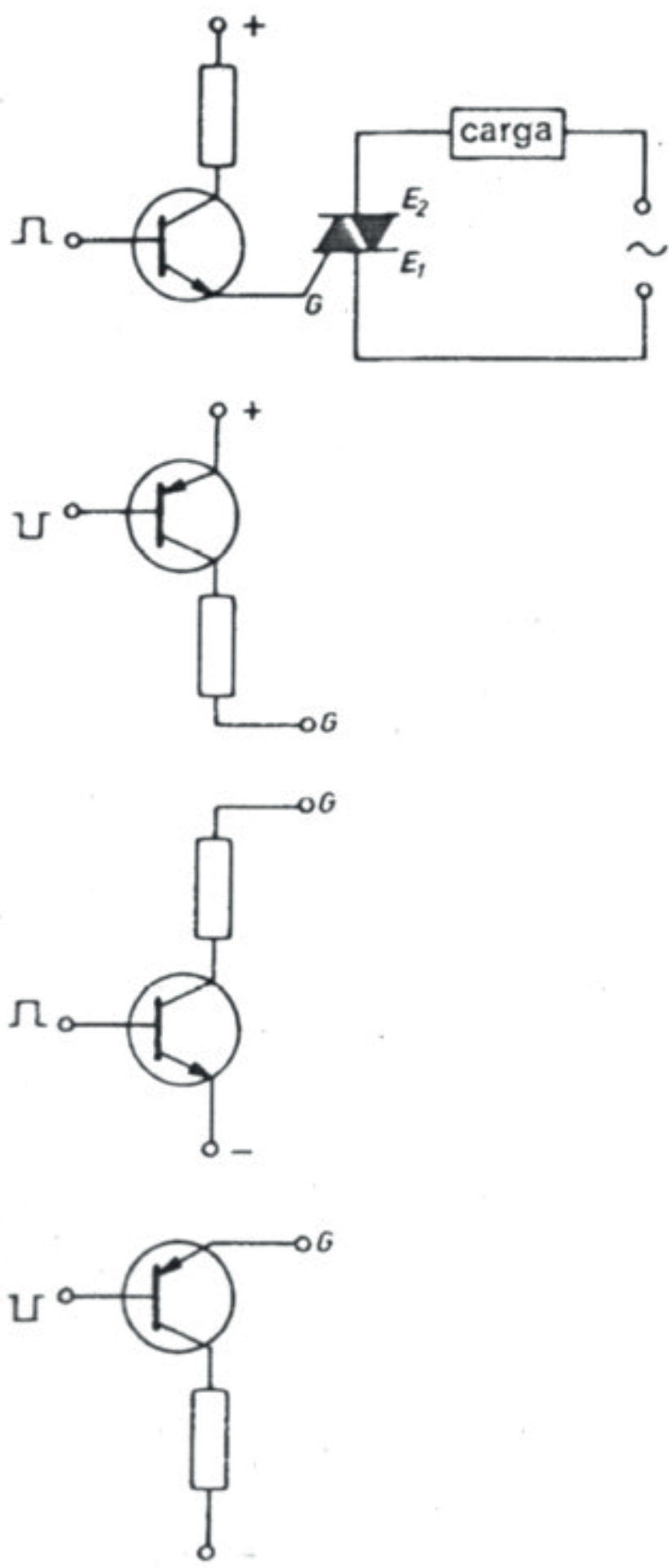

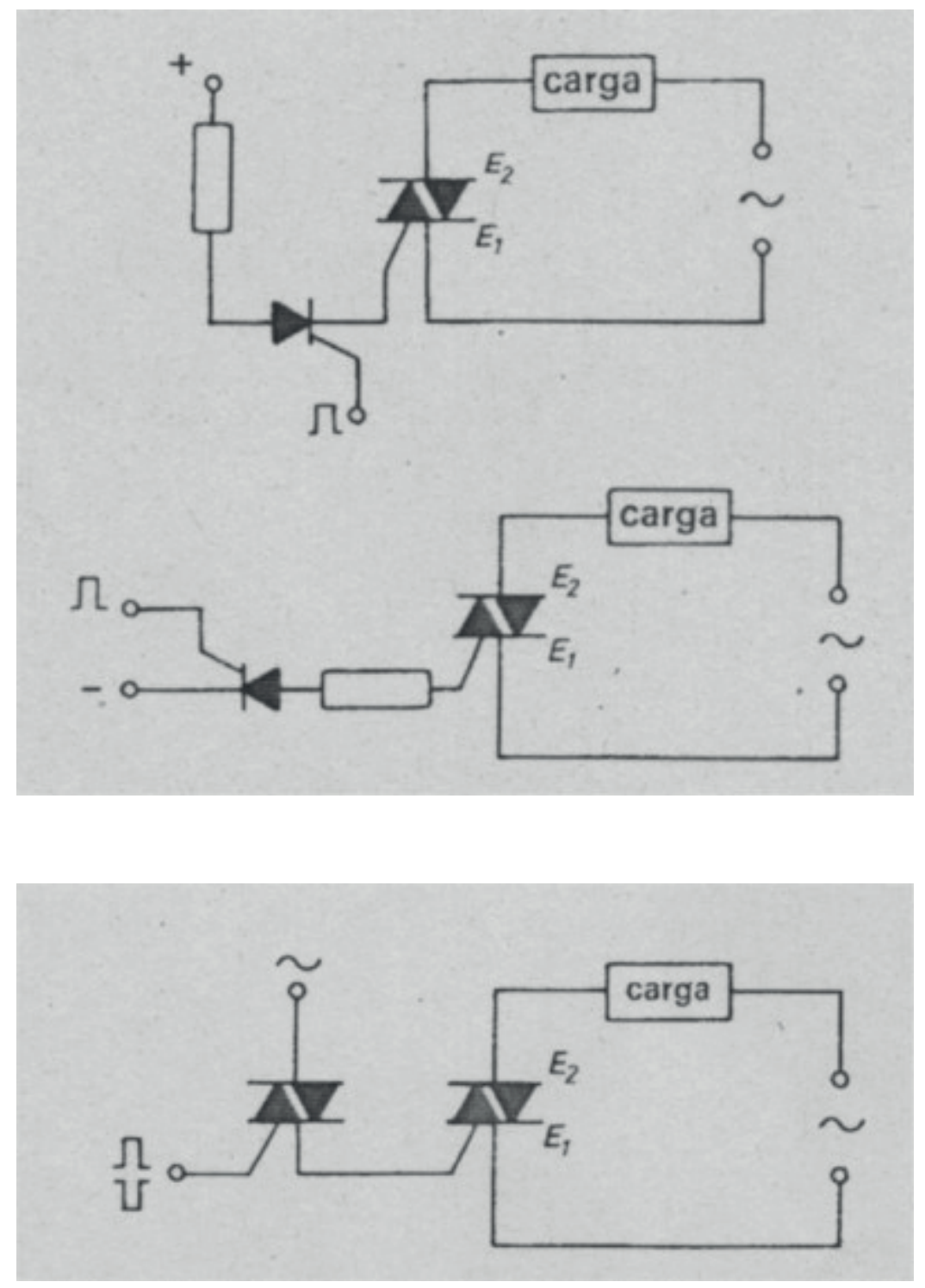

De estos últimos circuitos la simplificación que usaremos es la que se muestra, ya que, cuando el contacto A esté cerrado, la conducción en ambos semiciclos es evidente. Esta manera de simplificar el circuito resulta muy útil, sobre todo a la hora su funcionamiento: 


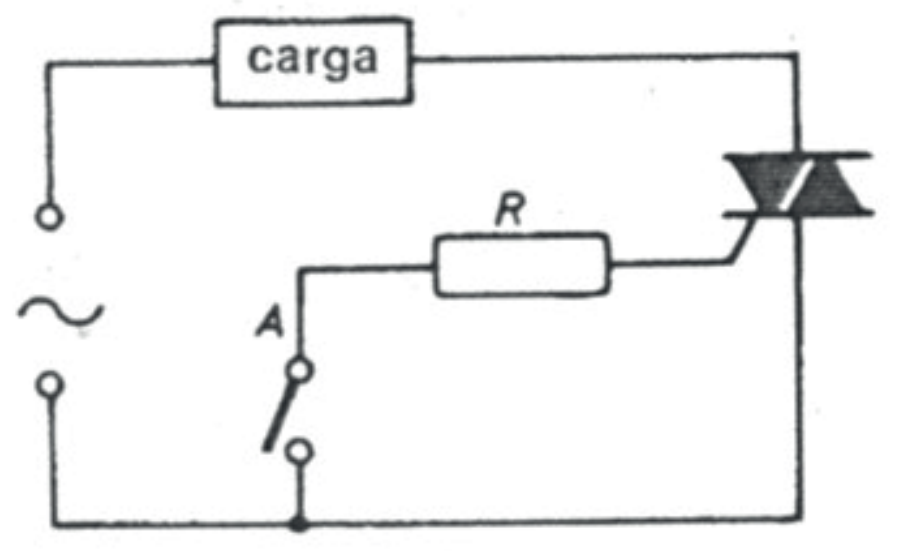

Una aplicación de estos dispositivos resulta en el siguiente control de temperatura discreto. El control se efectúa por el sistema de conmutación de todo o nada de un triac, resultando así un sistema proporcional.

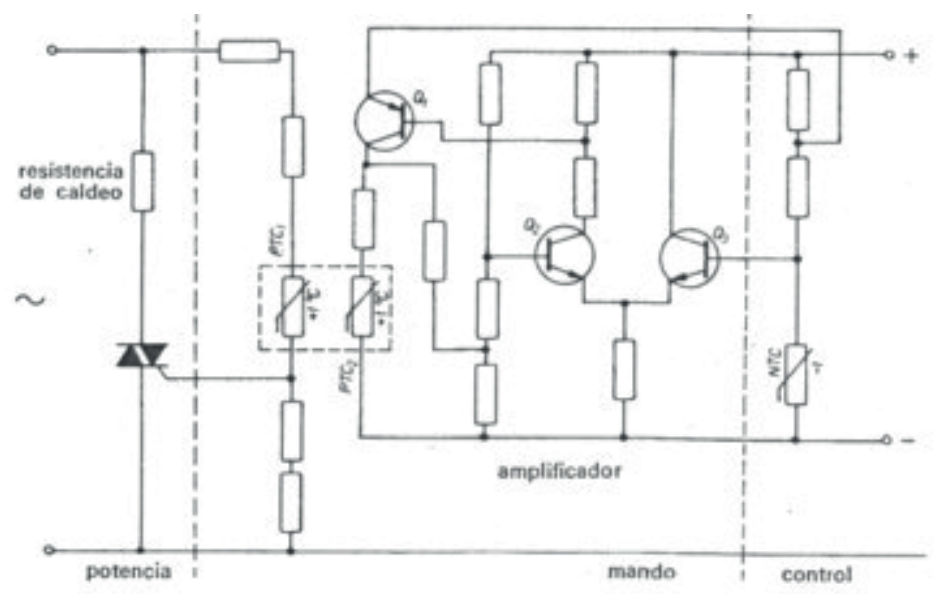

En este circuito, las resistencias térmicas PTC1 y PTC2 están acopladas térmicamente de forma que los cambios de temperatura de una influyen rápidamente en la otra. También es destacable el hecho de que el termistor de mando es de caldeo independiente, quedando de esta forma separado el circuito de mando del de potencia. Cuando la temperatura a regular, controlada por la NTC, es inferior a la deseada, la NTC tiene una resistencia elevada que mantiene bloqueado el circuito 
amplificador. Como consecuencia, la PTC2 no se calienta y tampoco lo hace la PTC1. En estas condiciones, el triac tiene en su puerta suficiente tensión como para estar disparado. Por lo tanto la resistencia de caldeo va aumentando la temperatura del medio. En el momento en que esta temperatura sea igual a la prefijada, la NTC pondrá en funcionamiento el amplificador y éste, a su vez, aumentará la temperatura de la PTC2. Con este aumento de temperatura y el consiguiente en la PTC1, bajará la tensión en la puerta del triac y dejará de conducir. A partir de aquí, los ciclos se repetirán en función de las temperaturas que le demos como consigna.

Otra aplicación importante de los triacs en el mando para la inversión del sentido de giro de un motor trifásico de c.a. El procedimiento electrónico, que sustituye al expuesto al principio de este artículo a través de contactores, es tal que: 


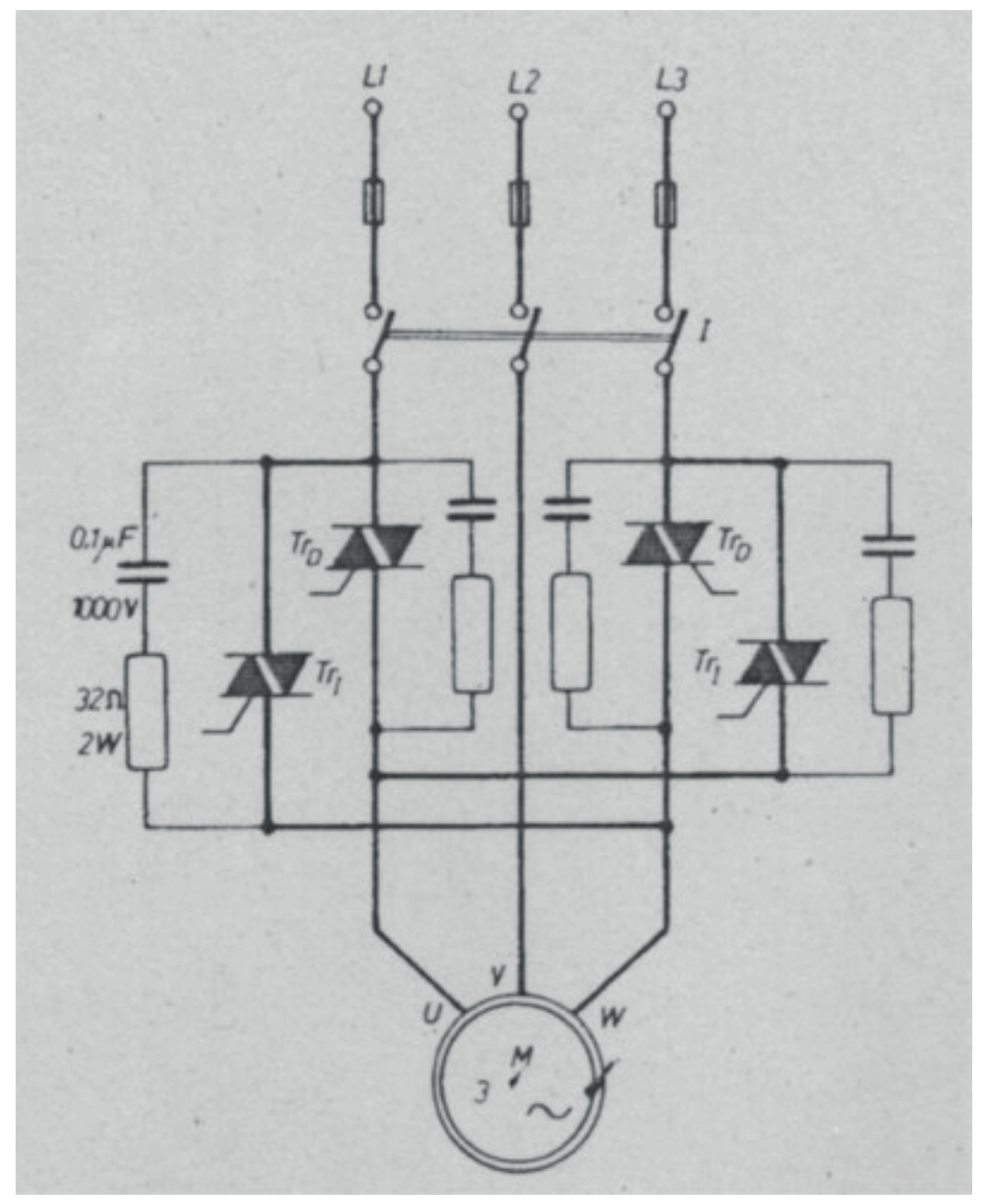

Aquí los triacs han sustituido a los contactores, lo que implica la eliminación de las partes móviles de los circuitos y la reducción de espacio. Esto se traduce en aumento de vida del equipo y mejor disponibilidad del montaje, sin hablar de la emisión de ruidos (mecánicos y eléctricos) de todo tipo. La inversión de la fase que cambia el sentido de giro se produce a través de los triacs, ya que la fase L2 puede alimentar al circuito directamente. Se aprecia cómo los circuitos de control accionan los triacs de dos en dos. Las redes RC proporcionan la seguridad del cebado de los triacs. 
Este montaje requiere una protección muy precisa cuando las inversiones de sentido de giro vayan a ser bruscas, o sea, cuando al desconectar el motor se invierta la marcha sin antes estar totalmente parado.

Para finalizar el presente artículo no podía dejarme en el tintero el transistor bipolar en conmutación. Cuando el transistor trabaja con señales fuertes, cambia de estado bruscamente, haciendo la función de un interruptor. En el circuito que a continuación presentamos, al cerrar el contacto A, circula corriente por la base, circulando a su vez una intensa corriente por colector y siendo la tensión Vce muy pequeña.

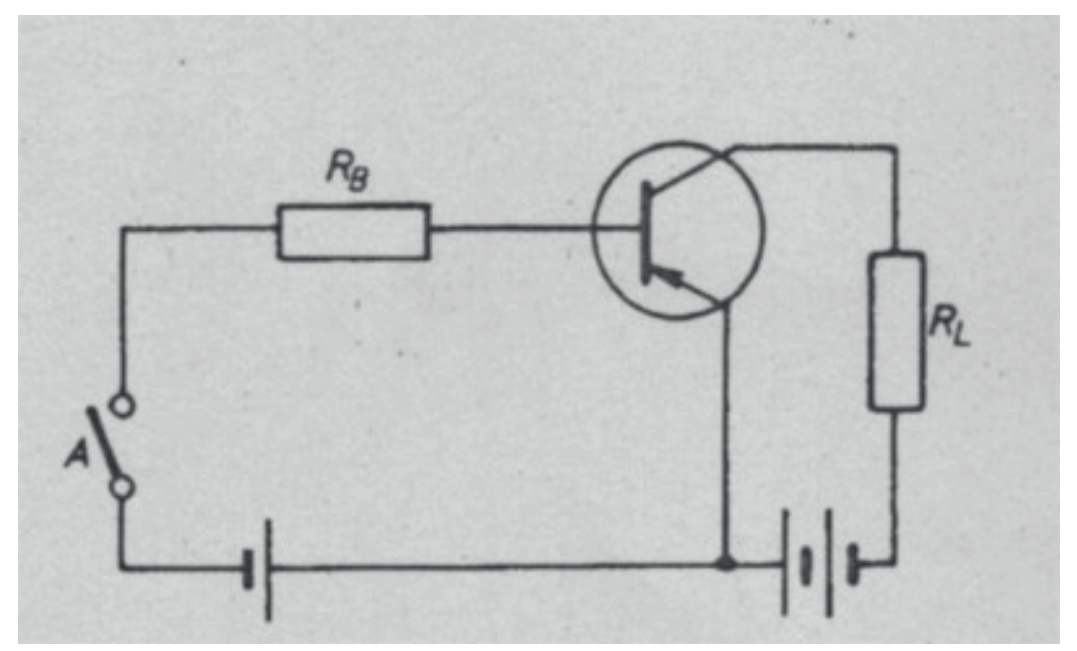




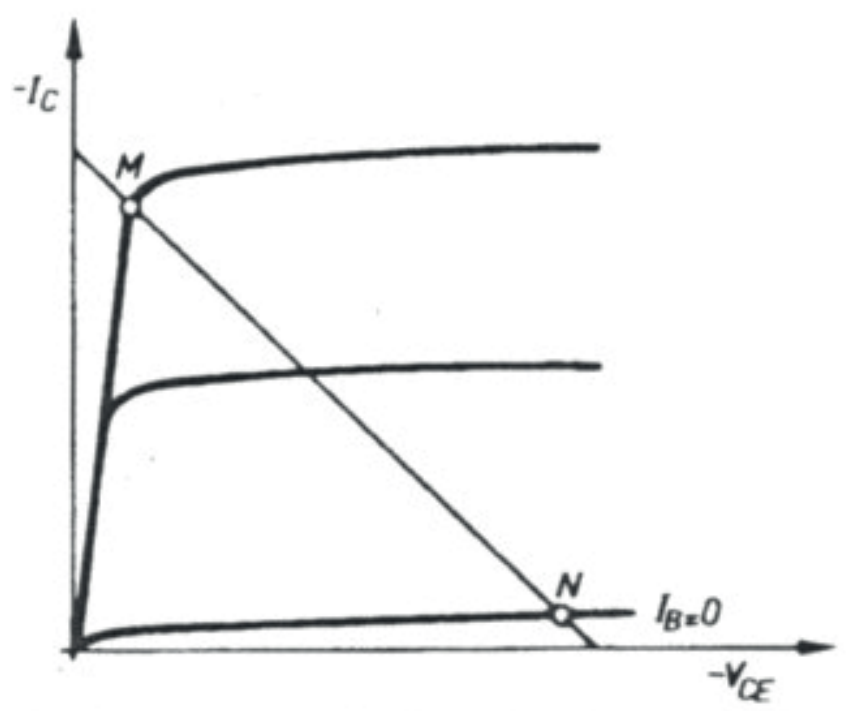

Observando sus curvas características basta ver el punto de trabajo del transistor M en estas circunstancias. Se puede decir que el transistor trabaja como un interruptor cerrado, dejando pasar la corriente y con una caída de tensión mínima. Con el contacto A abierto, el punto de trabajo es el N. Corriente de colector, casi nula, igual a la residual. De lo dicho se deduce que las cualidades que debe poseer el transistor para trabajar como interruptor son: pequeña resistencia a la conducción y gran resistencia de corte. Como se observará, en cualquiera de los dos puntos el consumo de potencia es mínimo.

El comportamiento de la conmutación ante cargas de distinta índole es muy distinto y merece la pena tener en cuenta estas diferencias. En un transistor con carga óhmica, la conexión y desconexión del circuito obliga al punto de trabajo a desplazarse a lo largo de la recta de carga. En algunos casos la potencia disipada es la misma, a saber: 


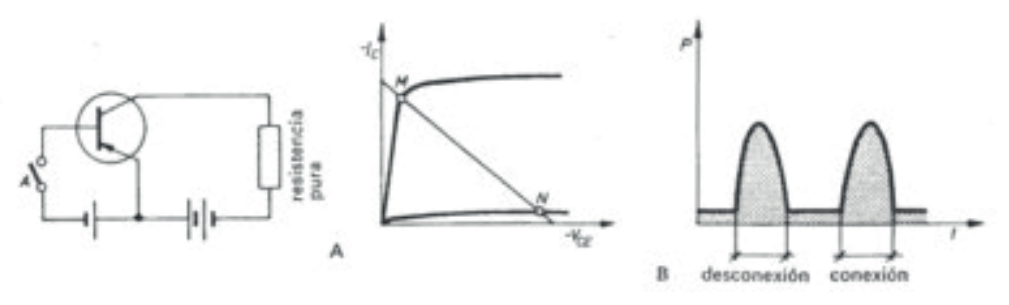

En un transistor con carga capacitiva, en la conexión se crea una sobreintensidad, siendo la tensión Vce aun alta, con el consiguiente aumento de potencia. Para disminuirla, puede conectarse una resistencia en serie. En la desconexión, la corriente decrece rápidamente y la potencia es pequeña: 

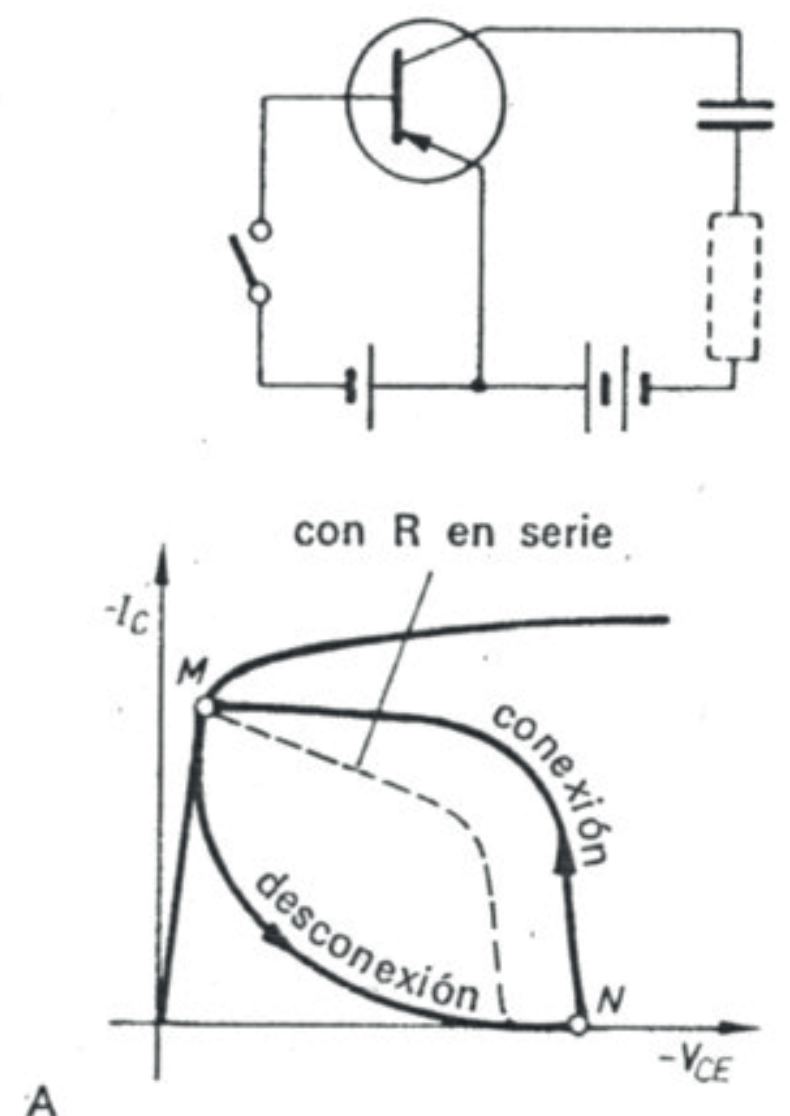

A

B

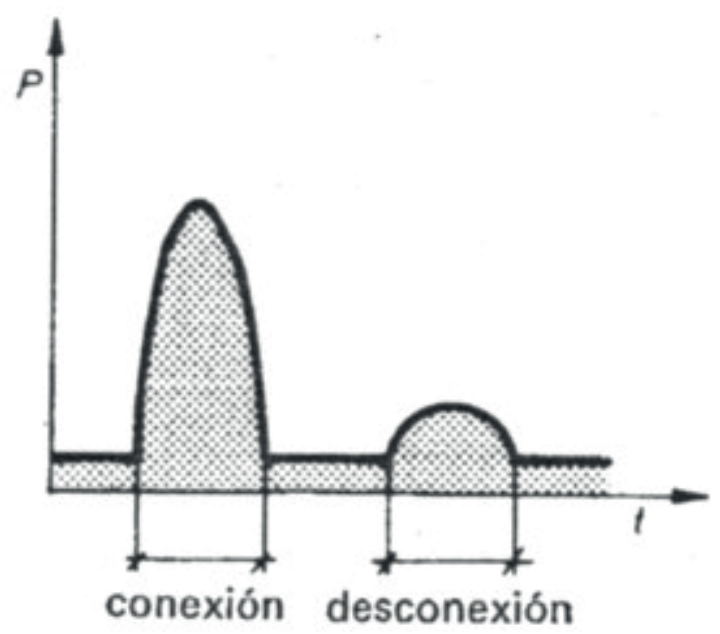

En un transistor con carga capacitiva, en la conexión se crea una sobreintensidad, siendo la tensión Vce aun alta, con el consiguiente aumento de potencia. Para 
disminuirla, puede conectarse una resistencia en serie. En la desconexión, la corriente decrece rápidamente y la potencia es pequeña:
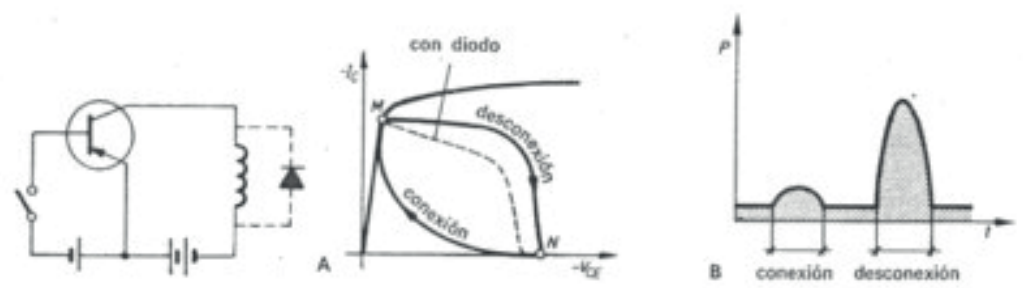

La respuesta de un transistor ante una señal no es instantánea. Si al circuito que a continuación mostramos, le introducimos una señal cuadrada, la respuesta con respecto a ésta será la que se ve en las señales que con aquel se muestran: 

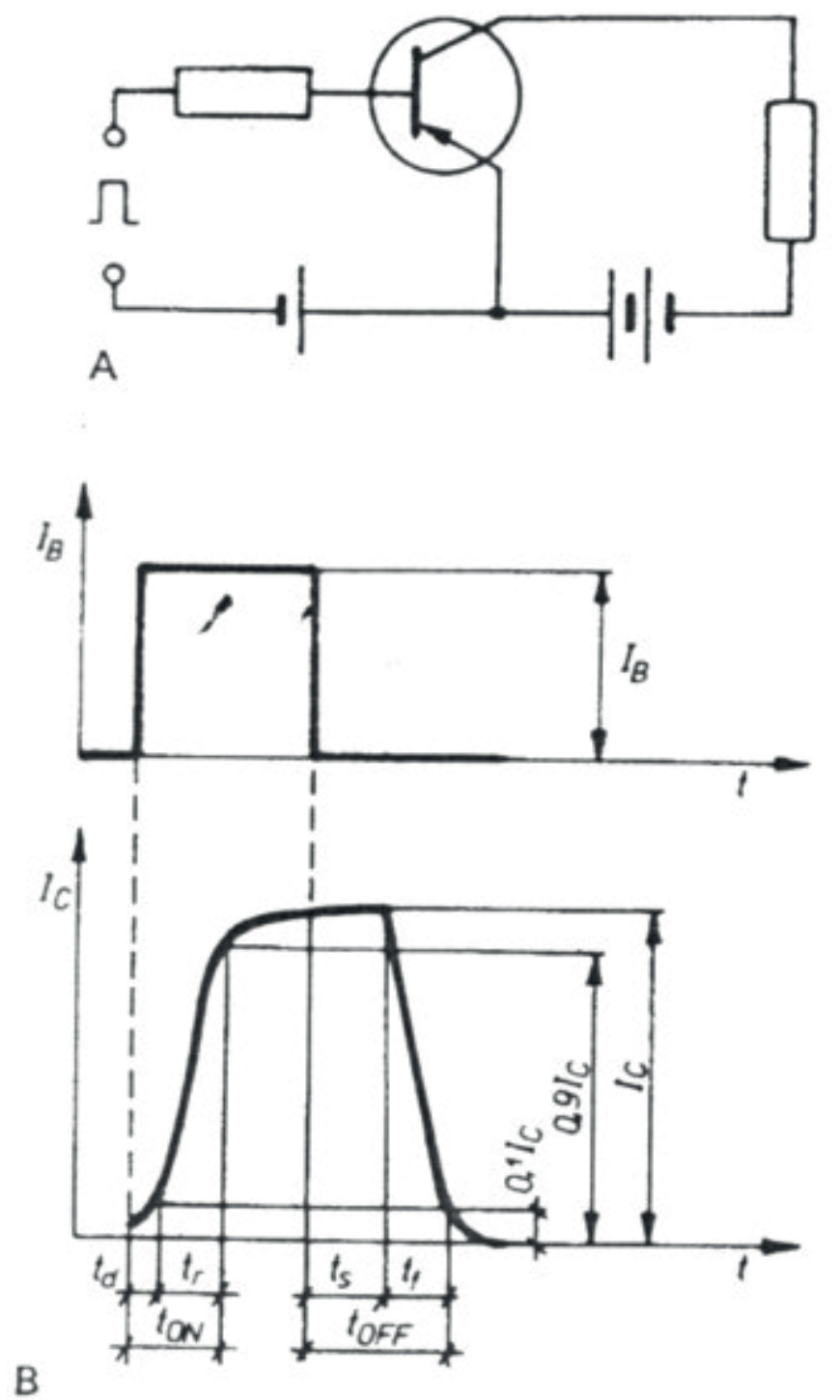

Analicemos los tiempos que observamos en las señales mostradas. El tiempo de retardo td es debido a que, al aplicar la señal de entrada, el transistor necesita un tiempo para cargar la capacidad de transición de la unión de emisor, pasando el transistor de la región de corte a la activa. Éste se divide en un tiempo, para que los portadores minoritarios puedan formar parte, propiamente dicha, de la corriente de 
colector, pues han de pasar por el emisor y la base, y otro tiempo, hasta que la corriente de colector alcanza el 10 \% de su valor máximo.

El tiempo de subida tr, es el que ha de transcurrir desde que la corriente de colector es del $10 \%$ al $90 \%$ de su valor máximo. La suma de td y tr se denomina tiempo de cierre ton.

El tiempo de almacenamiento ts es cuando la señal de entrada desaparece, en la base queda una carga de portadores minoritarios almacenados, precisándose un tiempo ts para que desaparezca. Durante este intervalo de tiempo, la corriente de colector ha descendido al $90 \%$ de su valor máximo.

El tiempo de caída tf se debe al mismo hecho que el tiempo de subida. La corriente de colector disminuye de forma exponencial desde el $90 \%$ al 10 de su valor máximo. La suma de ts y tf se denomina tiempo de bloqueo toff.

Para terminar quisiera exponer unos ejemplos prácticos, como el siguiente regulador de temperatura con transistores. La medida de temperatura se hará por un puente de medida al que se ha dotado de un termistor NTC y a la rama neutra del puente que se ha conectado a un amplificador diferencial, a saber: 


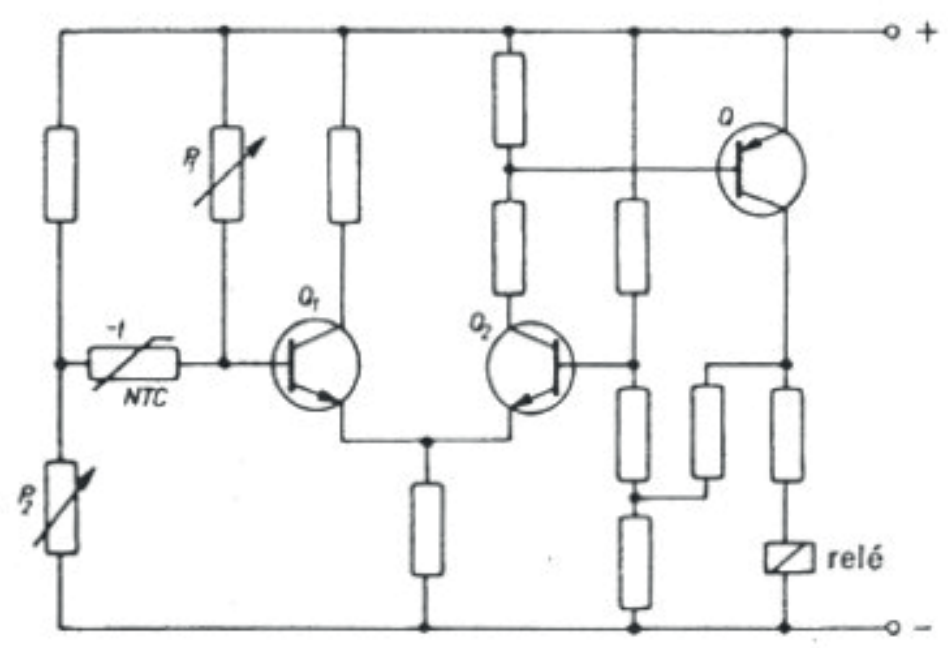

Cuando la NTC alcance la temperatura para la que ha sido ajustada, el amplificador diferencial hace conducir al transistor $Q$ y éste excita el relé, que hará la maniobra que corresponda.

Otra aplicación:

Aprovechando la ventaja de la rápida conmutación de los transistores, su uso en circuitos lógicos es muy interesante. En el circuito siguiente se muestra una puerta lógica, en la que, aplicando tensión positiva a una de las dos, o a las dos, entradas, la corriente circulará por $\mathrm{R}$, y en $\mathrm{S}$ habrá una tensión positiva respecto de masa. Este circuito se puede considerar como un conmutador OR: 


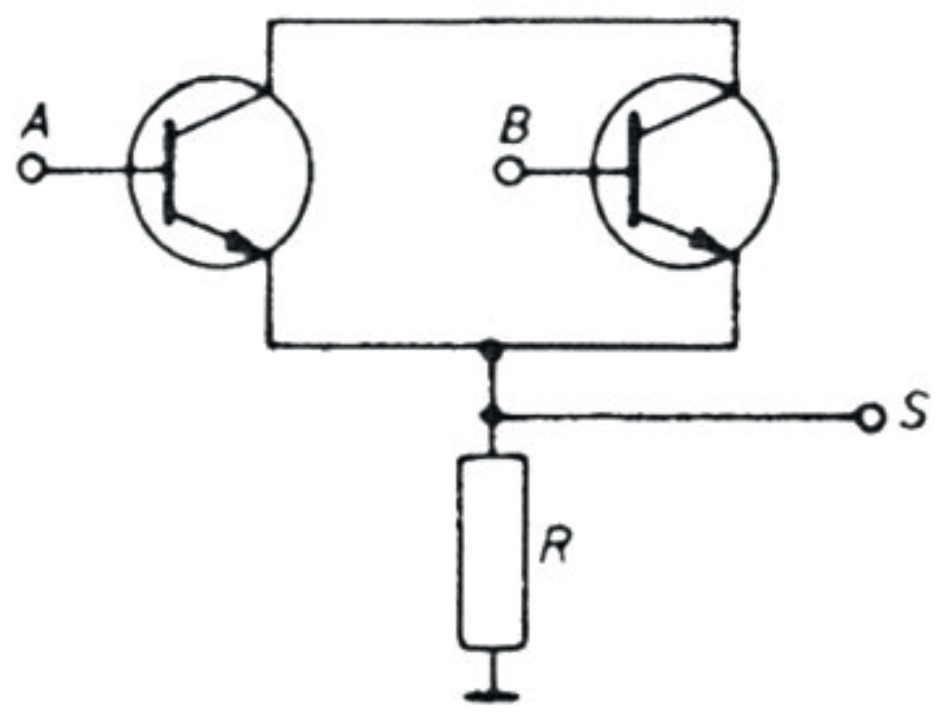

Este criterio podría extenderse a todas las puertas lógicas. Así, combinándolo con diodos, se obtendría la conmutación lógica, que a continuación se muestra.

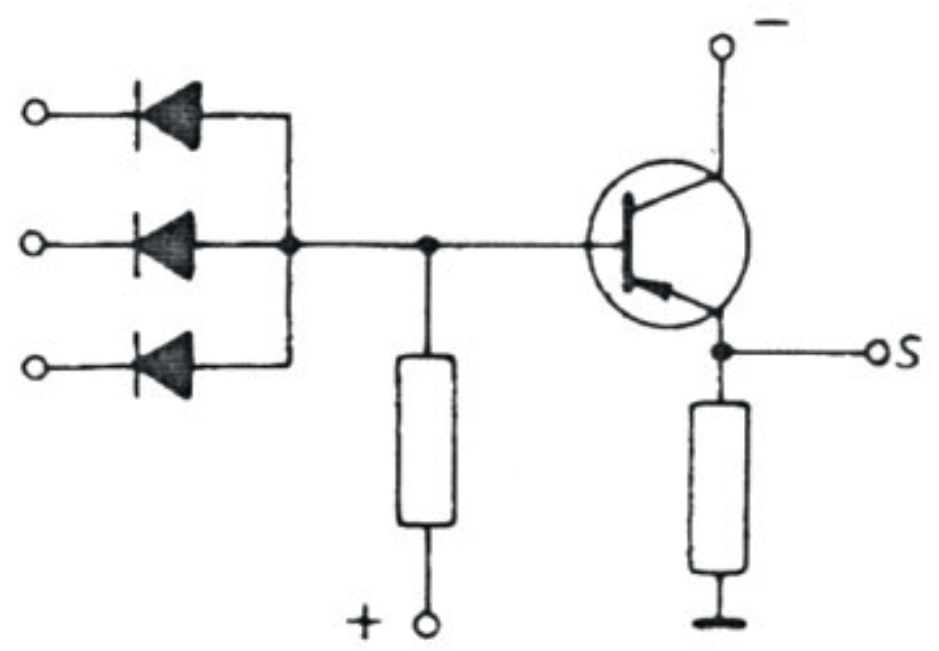

Con esto terminamos este artículo, compuesto en dos partes. En la primera, publicada en el número 50 de VA, expusimos los conceptos fundamentales y algunas 
aplicaciones de los relés y contactores. En esta segunda hemos dado una visión general de los interruptores electrónicos. 